Mini Review

\title{
Quality of life in the old age how to begin?
}

\section{Introduction}

Aging is a universal biological process, so we can affirm the positive percentage variation of the elderly population, the decrease in population growth resulting from lower birth and fecundity rates due to changes in behavior in the present society, which graphically passes to be represented by an inverted population pyramid.

For this reason, legislators, entities and civil society representatives, as well as social movements, have been engaged in establishing public policies aimed at promoting health and preventing diseases in the aging process, which provide quality of life for the elderly.

Scientifically, its known that aging is associated with the accumulation of molecular and cellular losses, contributing to the decrease of the homeostasis stability capacity. The elderly inactivity can be the trigger of a vicious circle of social isolation, making it lack of vital capacity for simple and daily tasks.

With the intention of responding to these challenges, the "World Report on Aging and Health" (WHO, 2015) ${ }^{1}$ was established to recommend equally profound changes in the way policies are formulated and health services provided to aging populations.

According to the Report, "There is no more typically old person", because there is a great diversity of characteristics. Some active seniors over 80 years old have levels of physical and mental capacity comparable to that of many 20 -year-olds.
Volume 3 Issue 6 - 2018

\author{
Renata Jabour Saraiva,' Ermelinda Maria \\ Bernardo Gonçalves, ${ }^{2}$ Caroliny dos Santos \\ Guimarães da Fonseca ${ }^{3}$ \\ 'National Department of Distance Education, Estácio de Sá \\ University, Brazil \\ ${ }^{2}$ Faculty of Health Sciences, Intitute of Guarda, Guarda, Portugal \\ ${ }^{3}$ Postgraduation Department, European University of the \\ Atlantic, Spain
} Postgraduation Department, European University of the Atlantic, Santander, Spain, Tel +55219648I-I391,

Email enfcarolimyguimaraes@gmail.com Received: August 08, 2018 | Published: November 03,
2018

These results contributed to the new assistance models, aiming at the health promotion, diseases prevention and the elderly priorities identification, with a view to maintaining or restoring their functional and cognitive capacity and their autonomy to achieve quality of life.

Recent studies around the world show that physical activity positively influences physical health and cognition throughout life. There are determining factors as described in the graph, which directly contribute to the elderly quality of life (Figure 1).

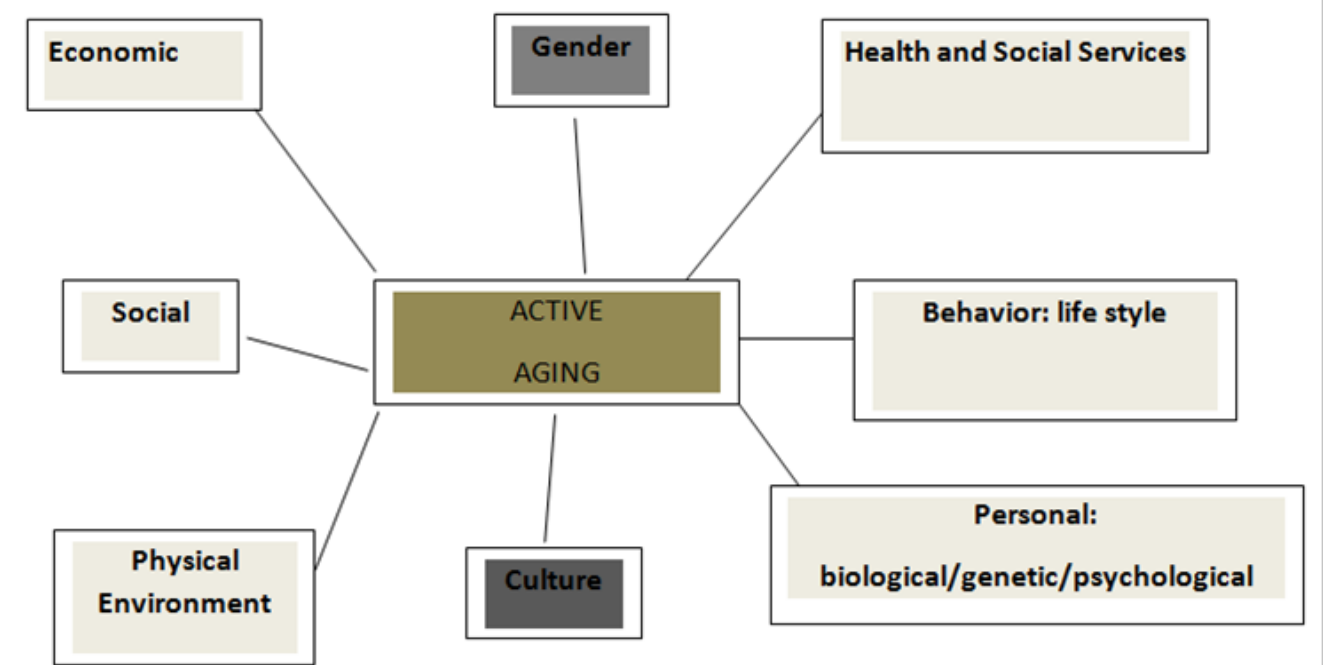

Figure I Factors as described in the graph, which directly contribute to the elderly quality of life.

According to Fernandez-Ballesteros, ${ }^{2}$ the public policies directed to the elderly need to involve four types of components:

Reduce risk factors associated with major diseases and increase factors that favor behavioral health and fitness:

i. Ensure adequate food throughout life;

ii. Prevent smoking and do not exceed the limits of healthy alcohol consumption; iii. Policies to control health status, prescribed drugs use and follow-up and compliance to medical treatments;

iv. Promote physical activity throughout the aging process.

Provide the protective factors of cognitive functioning:

i. Implement lifelong literacy programs as well as continuing training programs; 
ii. Give a chance to the practice of cognitive activity in old age;

iii. Foster involvement in cognitively demanding tasks;

iv. Spread the exercise of verbal and communication skills.

Encourage positive affect, control, and coping skills to deal with stress and problems:

i. Articulate pleasant events in old age, as preventive factors of depression and isolation;

ii. Motivate active and appropriate attitude to face difficulties, anxiety and conflicts;

iii. Bring confidence in their abilities;

iv. Propagate positive thinking and the control perception.

Provide psychosocial functioning and participation:

i. Promote the autonomy and participation in decision making of the elderly;

ii. Combat negative images about old age and aging;

iii. Encourage confidence in collective capacities;

iv. Generate pro-social behaviors;

v. Boost social participation.

When doing this therapy, health professionals begin to modify their actions in clinical practice, starting to have competences based on the collaborative relationship with a focus on the resolutiveness of their actions, aiming at reciprocity between involved professionals, elderly and family in the pursuit of pleasure to live well and healthy.

Based on the above, the elderly physical activity practice is based on critical judgment, demonstrating that it is essential to obtain the essence of the phenomenon, through the intersubjectivity of the involved people, the understanding of the experiences meaning, with the intention of fostering the teaching and learning of self-care, aiming at the quality of active life.

More deeply information on the subject can be found in "The Sexuality Interfaces of the Elderly: in the view of health professionals," our most recent book - Ed. Appris. Curitiba. 2017.

\section{Acknowledgments}

None.

\section{Conflicts of interest}

The author declares no conflicts of interest.

\section{References}

1. WHO. National health organization. World report on aging and health Switzerland; 2015.

2. Fernandez bR. Envejecimento activo - contribuiciones de la psicologia. edn. Pirámide. Madri; 2009:40-41. 